\title{
Sleep Duration and Sleep Quality following Acute Mild Traumatic Brain Injury: A Propensity Score Analysis
}

\author{
Ting-Yun Huang, ${ }^{1}$ Hon-Ping Ma, ${ }^{1,2}$ Shin-Han Tsai, ${ }^{1,2,3}$ Yung-Hsiao Chiang, ${ }^{4,5,6}$ \\ Chaur-Jong $\mathrm{Hu}^{7}$ and Juchi $\mathrm{Ou}^{8}$ \\ ${ }^{1}$ Department of Emergency Medicine, Shuang-Ho Hospital, Taipei Medical University, New Taipei City 235, Taiwan \\ ${ }^{2}$ Department of Emergency Medicine, Taipei Medical University, Taipei 110, Taiwan \\ ${ }^{3}$ College of Public Health and Nutrition, Taipei Medical University, Taipei 110, Taiwan \\ ${ }^{4}$ Department of Neurosurgery, Taipei Medical University, Taipei 110, Taiwan \\ ${ }^{5}$ Translational Research Laboratory, Cancer Center, Taipei Medical University, Taipei 110, Taiwan \\ ${ }^{6}$ Department of Surgery, College of Medicine, Taipei Medical University, Taipei 110, Taiwan \\ ${ }^{7}$ Department of Neurology, Shuang-Ho Hospital, Taipei Medical University, New Taipei City 235, Taiwan \\ ${ }^{8}$ Department of Emergency Medicine, Shuang-Ho Hospital, Taipei Medical University, No. 291 Zhongzheng Road, \\ Zhonghe District, New Taipei City 235, Taiwan
}

Correspondence should be addressed to Juchi Ou; juchi@tmu.edu.tw

Received 10 December 2014; Accepted 6 March 2015

Academic Editor: Jiyao Jiang

Copyright (C) 2015 Ting-Yun Huang et al. This is an open access article distributed under the Creative Commons Attribution License, which permits unrestricted use, distribution, and reproduction in any medium, provided the original work is properly cited.

Introduction. Mild traumatic brain injury (mTBI) has been widely studied and the effects of injury can be long term or even lifelong. This research aims to characterize the sleep problems of patients following acute mTBI. Methods. A total of 171 patients with mTBI within one month and 145 non-mTBI controls were recruited in this study. The questionnaire, Pittsburgh Sleep Quality Index (PSQI), was used to evaluate seven aspects of sleep problems. A propensity score method was used to generate a quasirandomized design to account for the background information, including gender, age, Beck's Anxiety Index, Beck's Depression Index, and Epworth Sleepiness Scale. The effect was evaluated via cumulative logit regression including propensity scores as a covariate. Results. Before adjustment, about $60 \% \mathrm{mTBI}$ patients and over three quarters of control subjects had mild sleep disturbance while one third mTBI patients had moderate sleep disturbance. After adjusting by the propensity scores, the scores of sleep quality and duration were significant between mTBI and control groups. Conclusion. Our study supports that sleep problem is common in mTBI group. After adjusting the confounders by propensity score, sleep duration and subjective sleep quality are the most frequently reported problems in mTBI patients within one month after the injury.

\section{Introduction}

More than a million people in the United States are affected by traumatic brain injury (TBI) annually [1]. The severe TBI typically results in disability or death, and TBI of any severity usually can affect the patient's physical, cognitive, and emotional wellbeing [2]. More than $80 \%$ of patients with TBI are classified as mild cases (mTBI), and most of mTBI patients may not have strongly and immediately uncomfortable feeling to this kind of injury. However, the effects of the mTBI can be on the long term or even lifelong [3-5]. Sleep problems are one category of the most commonly reported symptoms $[6,7]$. Sleep disturbance is also associated with increased risk of depression and anxiety, which are common after an event with mental or physical stress [8]. However, the sleep problems that might occur following an $\mathrm{mTBI}$ have yet to be fully characterized.

Pittsburgh Sleep Quality Index (PSQI), which is divided into 7 components, is a questionnaire frequently used for the evaluation of sleep problems in clinical and healthy 
populations [9]. In previous studies, a 3-factor model of the PSQI provided more accurate results on sleep disturbances than a global analysis did [10-13]. In an observational study, one main problem is that the case (exposed) and control groups may not be comparable and the outcomes might not represent a causal effect. One solution is the propensity score introduced by Rosenbaum and Rubin [14] in order to control the distributions of the unbalance covariables between case and control groups.

Therefore, this study aimed to determine the patterns of sleep problem associated with the mTBI by use of the PSQI. Specifically, we performed an analysis by the propensity score model to describe the characteristics of sleep problems among the patients following acute mTBI.

\section{Methods}

2.1. Participants and Procedure. All of the mTBI patients aged $\geq 17$ years who were admitted to any of the 3 affiliated hospitals of Taipei Medical University (TMU) between March 2010 and February 2013 were recruited. The definition of mTBI was based on the diagnostic criteria established by the American Congress of Rehabilitation Medicine, which consist of a Glasgow Coma Scale (GCS) score of 13-15 at presentation, loss of consciousness for $<30 \mathrm{~min}$, and normal head computed tomography findings. Patients who had a history of cerebrovascular disease, psychiatric comorbidities, epilepsy, alcohol abuse, sleep-wake modifying treatment, previous TBI, or severe systemic medical illness were excluded. In addition, volunteers who were older than 17 years old and did have no brain injury were recruited into the control group. The exclusion criteria for the control participants were the same as those for the mTBI patients. All patients were initially contacted by telephone and 675 mTBI patients were recruited. Among the mTBI patients, 171 (25.33\%) provided informed consent and completed a baseline assessment during an initial evaluation within 1 month of experiencing an mTBI. The study protocol was approved by the Joint Institution Review Board at TMU.

\subsection{Measures}

Pittsburg Sleep Quality Index (PSQI). The PSQI is a 19-item self-reported instrument designed to measure a person's sleep quality and patterns of sleep. It contains 7 domains: duration of sleep, sleep syndrome, sleep latency, daytime dysfunction caused by sleepiness, sleep efficiency, overall sleep quality, and use of sleep medications [9]. Each domain is scored from 0 to 3 , with a higher value indicating poorer sleep quality and a clinical cutoff point of 5. The Chinese version of the PSQI has been validated [15].

Epworth Sleepiness Scale (ESS). Daytime sleepiness was evaluated using the validated Chinese version of the ESS. Each question is rated on a 4 -point scale ( 0 , never; 3 , highly likely) [16], with a clinical cutoff point of 9. The Cronbach's alpha of the Chinese ESS is 0.81 and the test-retest reliability is 0.74 .
Beck Depression Inventory (BDI) II. The BDI is designed to measure depressive symptoms. This study used the Chinese version of the BDI II [17]. This questionnaire contains 21 items, scored on a scale of 0 (no problem) to 3 (severe problems). The total possible score ranges from 0 to 63 , with a clinical cutoff point of 9 . A higher BDI score indicates greater severity of depression [18].

Beck Anxiety Inventory (BAI). The Chinese version of the BAI was used. The BAI is a 21-item self-reported questionnaire designed to assess the symptoms of anxiety [19]. Each item is rated on a 4 -point scale. The total possible score ranges from 0 to 63 , with a clinical cutoff point of 7 . A higher score indicates more severe anxiety [20].

2.3. Statistical Analysis. The number of participants for each PSQI component was calculated, and differences in trends between the mTBI and control groups were compared using the Cochran-Armitage test. Also, the association between scales and the other confounders was assessed via Spearman's correlations. In this study, the participants in the control group were assumed to represent the general population. The control participant recruited without matching the age and gender of the mTBI group. In order to generate a quasirandomized design, the propensity score method was used to account for selection biases and potential confounding factors. The propensity scores were calculated by the logistic regression to estimate the probability of each patient on the basis of age, sex, and questionnaires. The best model was selected according to AIC stepwise algorithm. The effects for each component were assessed via cumulative logit regression. In all statistical tests, a $P$ value of $P<0.05$ was considered significant and all tests were 2 -tailed. The analyses were conducted using R software version 3.1.1.

\section{Results}

3.1. Demographic Information. In this study, we recruited 675 mTBI patients and 186 control participants, of whom 171 and 145 subjects, respectively, completed the PSQI and other questionnaires and signed the informed consent. The participants' demographic information is shown in Table 1. The percentages of men in two groups were not significantly different: $32 \%$ in the mTBI group and $38 \%$ in the control group $(P=0.06)$. The average years of education and percent of married participants were not different between the mTBI and control groups. The mean age of the mTBI patients was significantly higher than that of the control participants (38.57y versus $32.18 \mathrm{y} ; P<0.001$ ). More than $50 \%$ of the mTBI patients suffered from headache problems, and their BAI, BDI, and global PSQI scores were higher than those of the control group. As shown in Table 1, more than half of the mTBI patients had sustained their brain injuries in a motor accident, and a third of the group had sustained their injuries during a fall.

3.2. Analysis of PSQI Components before Adjustment. The stratified numbers of participants in each category of PSQI 
TABle 1: Demographic data of the mTBI and control groups.

\begin{tabular}{|c|c|c|c|}
\hline Variables & mTBI & Control & $P$ value \\
\hline$N$ & 171 & 145 & \\
\hline Glasgow outcome score & $14.98(0.12)$ & 15 & 0.99 \\
\hline Age at injury, mean (SD) & $38.57(15.09)$ & $32.18(10.63)$ & $<0.001$ \\
\hline Men, $n(\%)^{\#}$ & $56(32.74 \%)$ & $38(26.21 \%)$ & 0.06 \\
\hline Years of education (SD) & $15.33(1.95)$ & $14.93(2.23)$ & 0.88 \\
\hline Married, $n(\%)^{\#}$ & $59(34.50 \%)$ & $44(30.34 \%)$ & 0.27 \\
\hline Employed, $n(\%)^{\#}$ & $83(48.53 \%)$ & $70(48.28 \%)$ & 0.47 \\
\hline Headache, $n(\%)^{\#}$ & $107(62.57 \%)$ & $30(20.69 \%)$ & $<0.001$ \\
\hline \multicolumn{4}{|l|}{ Mechanism of injury, $n(\%)$} \\
\hline Transportation accident & $92(53.80)$ & - & \\
\hline Fall & $57(33.33)$ & - & \\
\hline Other & $22(12.87)$ & - & \\
\hline \multicolumn{4}{|l|}{ Psychological evaluations } \\
\hline BAI & $9.30(10.14)$ & $2.62(3.62)$ & $<0.001$ \\
\hline BDI & $8.75(8.13)$ & $5.18(7.24)$ & $<0.001$ \\
\hline ESS & $7.33(4.28)$ & $6.49(3.51)$ & 0.12 \\
\hline PSQI & $7.23(3.92)$ & $5.65(3.45)$ & $<0.001$ \\
\hline
\end{tabular}

\# $\mathrm{mTBI}$ and control groups compared using a proportional test. SD: standard deviation.

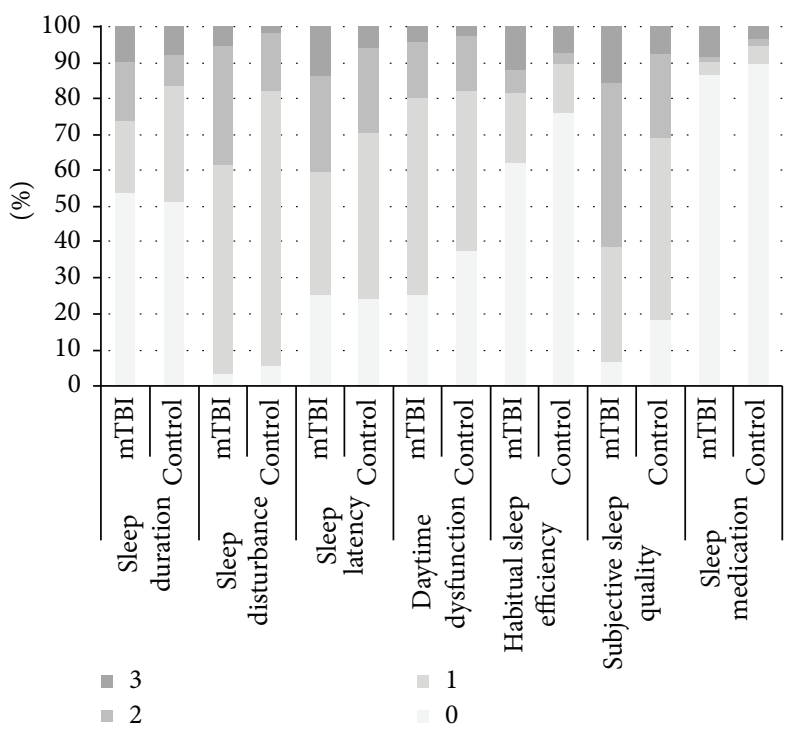

Figure 1: Percentage of each score for seven sleep components.

components are shown in Table 2 and the percentage of each score for each component are shown in Figure 1. The global PSQI score was different between two groups. However, four of them were not significantly different between mTBI and control groups. For both two groups, most of participants had no sleep duration problem, mild sleep latency, mild daytime dysfunction, and no use of sleep medication. The percentages of participants differed significantly between the mTBI and control groups in three components, sleep disturbance, habitual sleep efficiency, and subjective sleep quality. About $60 \%$ mTBI patients and over three quarters control subject had mild sleep disturbance while one third mTBI patients had moderate sleep disturbance. The percent of mild habitual sleep efficiency in mTBI group was significantly higher than that in the control group. Moreover, the percentage of moderate seep quality in mTBI group was higher than that in control groups. Overall, mTBIs showed more sleep disturbance, worse sleep efficiency and poorer sleep quality.

3.3. Associations. The $P$ value of the associations between sleep components and the other confounders are shown in Table 3. The components, sleep duration in mTBI group, daytime dysfunction in control group, and sleep medication in both groups, were related to the confounder, age. The BAI/BDI scores were not associated with sleep duration and the use of sleep medication for control group. The ESS was related to three components, sleep latency, daytime dysfunction, and subjective sleep quality.

3.4. Analysis of PSQI Subscores after Adjustment. The confounders were assessed for both groups via the logistic regression. After stepwise, the final model included four covariates, age, sex, BAI, and headache (as shown in Table 4). The propensity scores were calculated according to the final model above and the density of the propensity scores for two groups is shown in Figure 2. The results of group effect with and without propensity scores are shown in Table 5. The crude results from the cumulative logit models without propensity scores showed the significance in three components, sleep disturbance, habitual sleep efficiency, and 
TABLE 2: Numbers (percentages) of participants with each PSQI subscore in the mTBI and control groups.

\begin{tabular}{|c|c|c|c|c|}
\hline \multirow{2}{*}{ PSQI } & & \multicolumn{2}{|c|}{ Number (\%) } & \multirow[b]{2}{*}{$P$ value } \\
\hline & & $\begin{array}{c}\text { mTBI } \\
n=171\end{array}$ & $\begin{array}{l}\text { Control } \\
n=145\end{array}$ & \\
\hline \multirow{4}{*}{ Sleep duration } & $>7 \mathrm{~h}$ & $92(54)$ & $74(51)$ & \multirow{4}{*}{0.44} \\
\hline & $6-7 \mathrm{~h}$ & $34(20)$ & $47(32)$ & \\
\hline & $5-6 \mathrm{~h}$ & $28(16)$ & $12(8)$ & \\
\hline & $<5 \mathrm{~h}$ & $17(10)$ & $12(8)$ & \\
\hline \multirow{4}{*}{ Sleep disturbance } & None & $6(4)$ & $8(6)$ & \multirow{4}{*}{$<0.01$} \\
\hline & $1-9$ & $99(58)$ & $111(77)$ & \\
\hline & $10-18$ & $57(33)$ & $23(16)$ & \\
\hline & $19-27$ & $9(5)$ & $3(2)$ & \\
\hline \multirow{4}{*}{ Sleep latency } & $<15$ min and not during the previous month & $43(25)$ & $35(24)$ & \multirow{4}{*}{0.10} \\
\hline & $16-30 \mathrm{~min}$ and less than once/wk & $59(35)$ & $67(46)$ & \\
\hline & $31-60 \mathrm{~min}$ and once or twice/wk & $45(26)$ & $34(23)$ & \\
\hline & $>60 \mathrm{~min}$ and $>3$ times/wk & $24(14)$ & $9(6)$ & \\
\hline \multirow{4}{*}{ Daytime dysfunction } & No problems & $43(25)$ & $54(37)$ & \multirow{4}{*}{0.07} \\
\hline & Minor problems & $94(55)$ & $65(45)$ & \\
\hline & Considerable problems & $26(15)$ & $22(15)$ & \\
\hline & Major problems & $8(5)$ & $4(3)$ & \\
\hline \multirow{4}{*}{ Habitual sleep efficiency } & $\geq 85 \%$ & $106(62)$ & $110(76)$ & \multirow{4}{*}{0.01} \\
\hline & $75 \%-84 \%$ & $33(19)$ & $20(14)$ & \\
\hline & $65 \%-74 \%$ & $11(6)$ & $4(3)$ & \\
\hline & $<65 \%$ & $21(12)$ & $11(8)$ & \\
\hline \multirow{4}{*}{ Subjective sleep quality } & Very good & $11(6)$ & $27(19)$ & \multirow{4}{*}{$<0.01$} \\
\hline & Relatively good & $55(32)$ & $73(50)$ & \\
\hline & Relatively poor & $78(46)$ & $34(23)$ & \\
\hline & Very poor & $27(16)$ & $11(8)$ & \\
\hline \multirow{4}{*}{ Use of sleep medication } & Never during the previous month & $148(87)$ & $130(90)$ & \multirow{4}{*}{0.14} \\
\hline & Less than once/wk & $6(4)$ & $7(5)$ & \\
\hline & Once or twice/wk & $2(1)$ & $3(2)$ & \\
\hline & $\geq 3$ times/wk & $15(9)$ & $5(3)$ & \\
\hline
\end{tabular}

TABle 3: $P$ value of Spearman's correlation among the PSQI subscores and age, BDI, BAI, and ESS score.

\begin{tabular}{|c|c|c|c|c|c|}
\hline & Group & Age & BAI & BDI & ESS \\
\hline \multirow{2}{*}{ Sleep duration } & mTBI & 0.01 & $<0.01$ & 0.02 & 0.6 \\
\hline & Control & 0.16 & 0.22 & 0.65 & 0.14 \\
\hline \multirow{2}{*}{ Sleep disturbances } & mTBI & 0.17 & $<0.01$ & $<0.01$ & 0.04 \\
\hline & Control & 0.58 & $<0.01$ & 0.01 & 0.04 \\
\hline \multirow{2}{*}{ Sleep latency } & mTBI & 0.67 & $<0.01$ & $<0.01$ & 0.55 \\
\hline & Control & 0.15 & $<0.01$ & $<0.01$ & 0.16 \\
\hline \multirow{2}{*}{ Daytime dysfunction } & mTBI & 0.09 & $<0.01$ & $<0.01$ & $<0.01$ \\
\hline & Control & 0.02 & $<0.01$ & $<0.01$ & $<0.01$ \\
\hline \multirow{2}{*}{ Habitual sleep efficiency } & mTBI & 0.29 & 0.01 & $<0.01$ & 0.62 \\
\hline & Control & 0.13 & 0.03 & 0.03 & 0.10 \\
\hline \multirow{2}{*}{ Subjective sleep quality } & mTBI & 0.92 & $<0.01$ & $<0.01$ & 0.06 \\
\hline & Control & 0.89 & $<0.01$ & $<0.01$ & $<0.01$ \\
\hline \multirow{2}{*}{ Use of sleep medication } & mTBI & 0.04 & $<0.01$ & 0.01 & 0.44 \\
\hline & Control & 0.04 & 0.16 & 0.15 & 0.73 \\
\hline
\end{tabular}


TABLE 4: Results of propensity score model.

\begin{tabular}{lcc}
\hline & Estimate & $P$ value \\
\hline Age & 0.05 & $<0.01$ \\
Sex & -1.28 & $<0.01$ \\
BAI & 0.19 & $<0.01$ \\
Headache & 1.74 & $<0.01$ \\
BDI & -0.02 & 0.38 \\
ESS & -0.02 & 0.58 \\
\hline & After stepwise & \\
& Estimate & $P$ value \\
\hline Age & 0.05 & $<0.01$ \\
Sex & -1.32 & $<0.01$ \\
BAI & 0.17 & $<0.01$ \\
Headache & 1.71 & $<0.01$ \\
\hline
\end{tabular}

subjective sleep quality. This is the same result as the result of the trend test. However, the results were different after adjusting by propensity scores. The cumulative logit model results for two significant group effects are shown in Table 6 . The proportional odds ratio of comparing mTBI to control groups on sleep duration was 0.49 . For the mTBI group, the odds of sleep duration less than 5 hours versus the sleep duration more than 5 hours are 0.49 times lower than those for controls after adjusting by propensity scores. For the other outcome, subjective sleep quality, the odds of very poor sleep quality versus the combined the other three categories are 2.075 times greater than those for controls.

\section{Discussion and Conclusion}

All of the mTBI patients in this study had suffered nonblast injuries [21-23]; therefore, the results represent a nonwarrelated scenario in the general population. Our results indicate that patients with mTBI experience increased risk of sleep problems in comparison with non-mTBI controls. After adjusting all other confounders, such as gender, age, depression, anxiety, and daytime sleepiness by propensity score analysis, the mTBI patients have different sleep duration and subjective sleep quality in the self-reported questionnaire. These findings are compatible with those from previous studies, which evaluated patients 3 months and 3 years after TBI $[7,24,25]$. Our study results also indicate that sleep problems typically occur in the acute stage immediately after an mTBI. Moreover, two sleep components, in terms of sleep duration and subjective sleep quality, were significantly different from the control group while the others showed no difference after adjusting by propensity scores as a covariate. In the study of Fichtenberg et al., poor sleep quality, including limited duration and efficiency of sleep, and insomnia were the 2 major sleep problems to affect TBI patients [26]. In two other previous studies, the quantitative electroencephalograms (qEEG) of mTBI and non-mTBI patients showed no significant differences $[27,28]$. However, in the study of Khoury et al., sleep architecture differed significantly

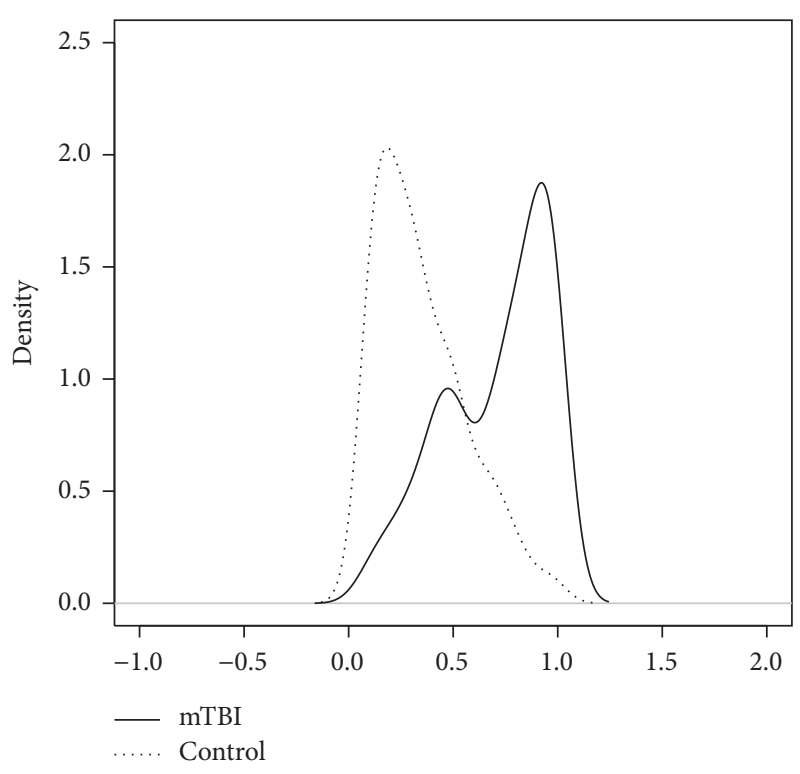

FIgUre 2: Propensity score density for mTBI (solid line) and control (dotted line) participants.

between mTBI with pain and control participants but sleep architectures of two groups were within normal ranges [29].

One finding of particular interest was that sleep problems following mild traumatic brain injury can be associated with anxiety and depression. Therefore, the group effect was evaluated after adjusting by the propensity score model including anxiety and depression scores in order to achieve the quasirandomized observation study. In the mTBI group, we observed that the PSQI subscore for sleep disturbance was moderately to strongly associate with the BAI score. We suggest that some features of anxiety, such as increased arousal at night, can lead to sleep disruption and then result in changes of sleep duration and subjective sleep quality [30].

There are a few limitations in the study. First, the subjective data were collected instead of objective data, such as adrenocorticotropic hormone (ACTH) and cortisol which were associated with sleep quality [31-33]. Second, long-term follow-up studies need to be considered for elucidating the disease course of sleep problems following mTBI.

In conclusion, our study results indicate the characteristics of sleep problems following mTBI. The patients with mTBI had significantly different sleep duration and sleep quality after adjusting all other confounders. These findings could potentially increase physicians' understanding of the consequences of the mTBI. Studies with longer-term followup and analyses of biomarkers such as ACTH and cortisol are recommended to facilitate the raising an optimal management of sleep disturbance in mTBI patients.

\section{Conflict of Interests}

The authors declare that there is no conflict of interests regarding the publication of this paper. 
TABLE 5: Results of mTBI effect via cumulative logit model with or without propensity score as a covariate.

\begin{tabular}{|c|c|c|c|c|}
\hline Model & Estimate & sd & $z$-value & $P$ value \\
\hline \multicolumn{5}{|l|}{ Sleep duration } \\
\hline Crude & 0.0694 & 0.2136 & 0.3249 & 0.75 \\
\hline Propensity score & -0.7122 & 0.2685 & -2.6525 & $<0.01$ \\
\hline \multicolumn{5}{|l|}{ Sleep disturbance } \\
\hline Crude & 0.9691 & 0.2496 & 3.8827 & $<0.01$ \\
\hline Propensity score & -0.0498 & 0.3087 & -0.1613 & 0.87 \\
\hline \multicolumn{5}{|l|}{ Sleep latency } \\
\hline Crude & 0.2998 & 0.2496 & 3.8827 & 0.14 \\
\hline Propensity score & -0.3154 & 0.2477 & -1.2734 & 0.20 \\
\hline \multicolumn{5}{|l|}{ Daytime dysfunction } \\
\hline Crude & 0.4126 & 0.2153 & 1.9166 & 0.06 \\
\hline Propensity score & -0.1134 & 0.2617 & -0.4332 & 0.66 \\
\hline \multicolumn{5}{|c|}{ Habitual sleep efficiency } \\
\hline Crude & 0.6535 & 0.2459 & 2.6572 & $<0.01$ \\
\hline Propensity score & 0.0722 & 0.3016 & 0.2394 & 0.81 \\
\hline \multicolumn{5}{|c|}{ Subjective sleep quality } \\
\hline Crude & 1.1907 & 0.2201 & 5.4096 & $<0.01$ \\
\hline Propensity score & 0.7300 & 0.2532 & 2.8831 & $<0.01$ \\
\hline \multicolumn{5}{|c|}{ Use of sleep medication } \\
\hline Crude & 0.3366 & 0.3522 & 0.9557 & 0.34 \\
\hline Propensity score & -0.5840 & 0.4656 & -1.2544 & 0.21 \\
\hline
\end{tabular}

TABLE 6: Results of the proportional-odds cumulative logit model.

\begin{tabular}{lcccc}
\hline & Model & Estimate & sd & 95\% CI \\
\hline Intercept & Sleep duration & & & \\
Intercept & $\log (P(>7 \mathrm{~h}) /(1-P(>7 \mathrm{~h})))$ & 1.2207 & 0.2641 & $(0.70,1.74)$ \\
Intercept & $\log (P(>6 \mathrm{~h}) /(1-P(>6 \mathrm{~h})))$ & 2.4835 & 0.2926 & $(1.91,3.06)$ \\
mTBI & $(P(>5 \mathrm{~h}) /(1-P(>5 \mathrm{~h})))$ & 3.5940 & 0.3403 & $(2.93,4.26)$ \\
\hline & & -0.7122 & 0.2685 & $(-1.24,-0.19)$ \\
& Subjective sleep quality & & & $(-1.32,-0.28)$ \\
& $\log (P(0) /(1-P(0)))$ & -0.8032 & -0.2837 & $(1.11,2.15)$ \\
mTBI & $\log (P(\leq 1) / P(>1))$ & 1.1130 & 2.1525 & $(3.30,4.67)$ \\
\hline
\end{tabular}

\section{Acknowledgments}

This study was supported by Grants NSC 98-2321-B-038-005MY3, NSC 101-2321-B-038-005, 103TMU-SHH-24, and DOH 101-TD-B-111-003.

\section{References}

[1] M. Faul, L. Xu, M. M. Wald, and V. G. Coronado, Traumatic Brain Injury in the United States: Emergency Department Visits, Hospitalizations, and Deaths, Centers for Disease Control and Prevention, National Centre for Injury Prevention and Control, Atlanta, Ga, USA, 2010, http://www.cdc.gov/TraumaticBrainInjury/.

[2] S. T. DeKosky, M. D. Ikonomovic, and S. Gandy, "Traumatic brain injury: football, warfare, and long-term effects," The New
England Journal of Medicine, vol. 363, no. 14, pp. 1293-1296, 2010.

[3] S. Thornhill, G. M. Teasdale, G. D. Murray, J. McEwen, C. W. Roy, and K. I. Penny, "Disability in young people and adults one year after head injury: prospective cohort study," British Medical Journal, vol. 320, no. 7250, pp. 1631-1635, 2000.

[4] J. F. Kraus, D. L. McArthur, T. A. Silverman, and M. Jayaraman, "Epidemiology of brain injury," in Neurotrauma, R. Narayan, J. Wilberger, and J. Povlishock, Eds., pp. 13-30, McGraw-Hill Professional, New York, NY, USA, 1996.

[5] P. J. Yates, W. H. Williams, A. Harris, A. Round, and R. Jenkins, "An epidemiological study of head injuries in a UK population attending an emergency department," Journal of Neurology, Neurosurgery \& Psychiatry, vol. 77, no. 5, pp. 699-701, 2006.

[6] H. J. Orff, L. Ayalon, and S. P. A. Drummond, "Traumatic brain injury and sleep disturbance: a review of current research," 
Journal of Head Trauma Rehabilitation, vol. 24, no. 3, pp. 155$165,2009$.

[7] H.-P. Ma, J.-C. Ou, C.-T. Yeh et al., "Recovery from sleep disturbance precedes that of depression and anxiety following mild traumatic brain injury: a 6-week follow-up study," $B M J$ Open, vol. 4, no. 1, Article ID e004205, 2014.

[8] E. O. Johnson, T. Roth, and N. Breslau, "The association of insomnia with anxiety disorders and depression: exploration of the direction of risk," Journal of Psychiatric Research, vol. 40, no. 8, pp. 700-708, 2006.

[9] D. J. Buysse, C. F. Reynolds III, T. H. Monk, S. R. Berman, and D. J. Kupfer, "The Pittsburgh sleep quality index: a new instrument for psychiatric practice and research," Psychiatry Research, vol. 28, no. 2, pp. 193-213, 1989.

[10] H. Burkhalter, S. M. Sereika, S. Engberg, A. Wirz-Justice, J. Steiger, and S. De Geest, "Structure validity of the Pittsburgh sleep quality index in renal transplant recipients: a confirmatory factor analysis," Sleep and Biological Rhythms, vol. 8, no. 4, pp. 274-281, 2010.

[11] J. C. Cole, S. J. Motivala, D. J. Buysse, M. N. Oxman, M. J. Levin, and M. R. Irwin, "Validation of a 3-factor scoring model for the Pittsburgh Sleep Quality Index in older adults," Sleep, vol. 29, no. 1, pp. 112-116, 2006.

[12] C. A. Magee, P. Caputi, D. C. Iverson, and X.-F. Huang, "An investigation of the dimensionality of the Pittsburgh sleep quality index in Australian adults," Sleep and Biological Rhythms, vol. 6, no. 4, pp. 222-227, 2008.

[13] A. Mariman, D. Vogelaers, I. Hanoulle, L. Delesie, E. Tobback, and D. Pevernagie, "Validation of the three-factor model of the PSQI in a large sample of chronic fatigue syndrome (CFS) patients," Journal of Psychosomatic Research, vol. 72, no. 2, pp. 111-113, 2012.

[14] P. R. Rosenbaum and D. B. Rubin, "The central role of the propensity score in observational studies for causal effects," Biometrika, vol. 70, no. 1, pp. 41-55, 1983.

[15] P.-S. Tsai, S.-Y. Wang, M.-Y. Wang et al., "Psychometric evaluation of the Chinese version of the Pittsburgh sleep quality index (CPSQI) in primary insomnia and control subjects," Quality of Life Research, vol. 14, no. 8, pp. 1943-1952, 2005.

[16] N.-H. Chen, M. W. Johns, H.-Y. Li et al., "Validation of a Chinese version of the epworth sleepiness scale," Quality of Life Research, vol. 11, no. 8, pp. 817-821, 2002.

[17] M. Lu, H. Che, and S. Chang, "Reliability and validity of the Chinese version of the Beck depression inventory II," Taiwanese Journal of Psychiatry, vol. 16, pp. 301-310, 2002 (Chinese).

[18] A. T. Beck, R. A. Steer, R. Ball, and W. F. Ranieri, "Comparison of Beck depression inventories-IA and -II in psychiatric outpatients," Journal of Personality Assessment, vol. 67, no. 3, pp. 588$597,1996$.

[19] S. Cheng, C. Wong, and K. Wong, "A study of psychometric properties, normative scores, and factor structure of the beck anxiety inventorythe Chinese version," Chinese Journal of Clinical Psychology, vol. 10, pp. 4-6, 2002.

[20] A. T. Beck and R. A. Steer, Beck Anxiety Inventory Manual, Harcourt Brace and Company, San Antonio, Tex, USA, 1993.

[21] C. W. Hoge, D. McGurk, J. L. Thomas, A. L. Cox, C. C. Engel, and C. A. Castro, "Mild traumatic brain injury in U.S. soldiers returning from Iraq," The New England Journal of Medicine, vol. 358, no. 5, pp. 453-463, 2008.

[22] D. D. Luxton, D. Greenburg, J. Ryan, A. Niven, G. Wheeler, and V. Mysliwiec, "Prevalence and impact of short sleep duration in redeployed OIF soldiers," Sleep, vol. 34, no. 9, pp. 1189-1195, 2011.
[23] A. J. MacGregor, A. L. Dougherty, J. J. Tang, and M. R. Galarneau, "Postconcussive symptom reporting among us combat veterans with mild traumatic brain injury from operation iraqi freedom," Journal of Head Trauma Rehabilitation, vol. 28, no. 1, pp. 59-67, 2013.

[24] C. R. Baumann, E. Werth, R. Stocker, S. Ludwig, and C. L. Bassetti, "Sleep-wake disturbances 6 months after traumatic brain injury: a prospective study," Brain, vol. 130, no. 7, pp. 1873$1883,2007$.

[25] J. Kempf, E. Werth, P. R. Kaiser, C. L. Bassetti, and C. R. Baumann, "Sleep-wake disturbances 3 years after traumatic brain injury," Journal of Neurology, Neurosurgery and Psychiatry, vol. 81, no. 12, pp. 1402-1405, 2010.

[26] N. L. Fichtenberg, R. D. Zafonte, S. Putnam, N. R. Mann, and A. E. Millard, "Insomnia in a post-acute brain injury sample," Brain Injury, vol. 16, no. 3, pp. 197-206, 2002.

[27] N. Gosselin, M. Lassonde, D. Petit et al., "Sleep following sportrelated concussions," Sleep Medicine, vol. 10, no. 1, pp. 35-46, 2009.

[28] G. J. Lavigne, A. Nashed, C. Manzini, and M. C. Carra, "Does sleep differ among patients with common musculoskeletal pain disorders?" Current Rheumatology Reports, vol. 13, no. 6, pp. 535-542, 2011.

[29] S. Khoury, F. Chouchou, F. Amzica et al., "Rapid EEG activity during sleep dominates in mild traumatic brain injury patients with acute pain," Journal of Neurotrauma, vol. 30, no. 8, pp. 633641, 2013.

[30] T. W. Uhed, "Anxiety disorders," in Principles and Practice of Sleep Medicine, M. H. Kryger, T. Roth, and W. C. Dement, Eds., pp. 1123-1139, W.B. Saunders, Philadelphia, Pa, USA, 3rd edition, 2000.

[31] S. Marcus, J. F. Lopez, S. McDonough et al., "Depressive symptoms during pregnancy: impact on neuroendocrine and neonatal outcomes," Infant Behavior \& Development, vol. 34, no. 1, pp. 26-34, 2011.

[32] L. M. Tomfohr, K. M. Edwards, and J. E. Dimsdale, "Is obstructive sleep apnea associated with cortisol levels? A systematic review of the research evidence," Sleep Medicine Reviews, vol. 16, no. 3, pp. 243-249, 2012.

[33] S. van Liempt, J. Arends, P. J. M. Cluitmans, H. G. M. Westenberg, R. S. Kahn, and E. Vermetten, "Sympathetic activity and hypothalamo-pituitary-adrenal axis activity during sleep in post-traumatic stress disorder: a study assessing polysomnography with simultaneous blood sampling," Psychoneuroendocrinology, vol. 38, no. 1, pp. 155-165, 2013. 


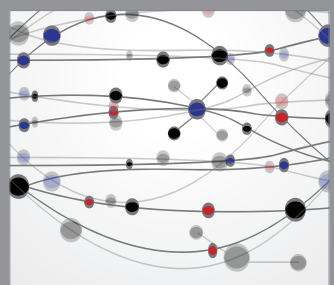

The Scientific World Journal
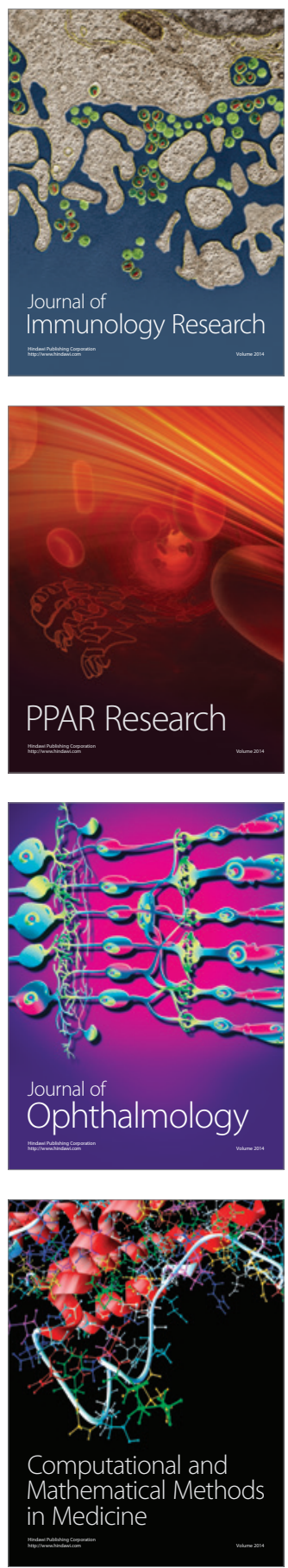

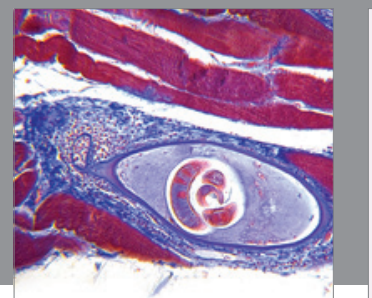

Gastroenterology

Research and Practice
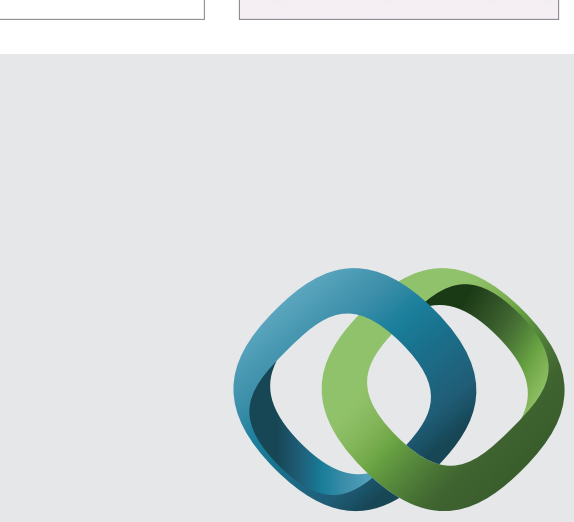

\section{Hindawi}

Submit your manuscripts at

http://www.hindawi.com
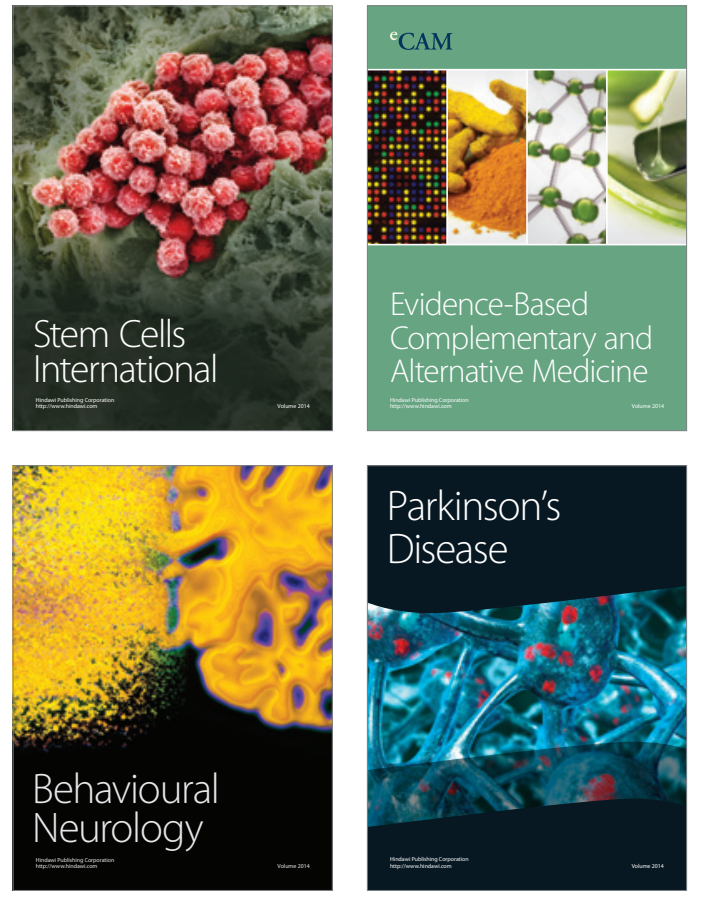
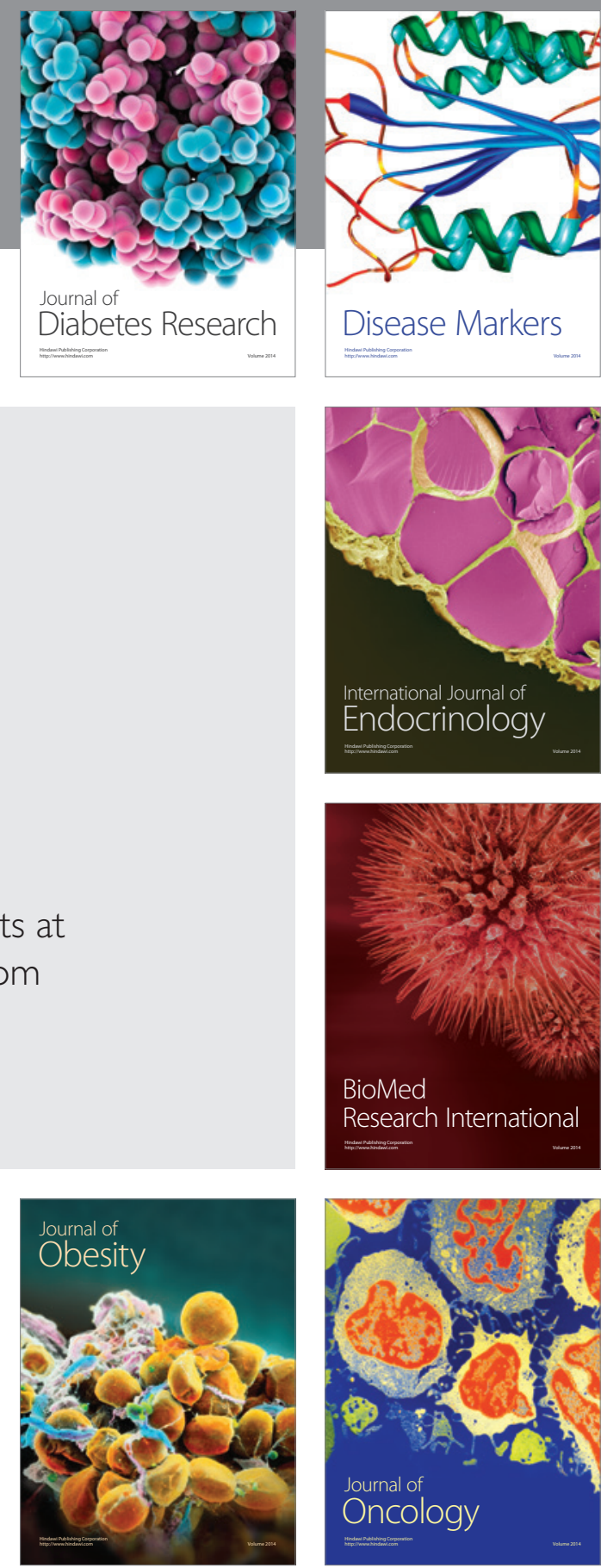

Disease Markers
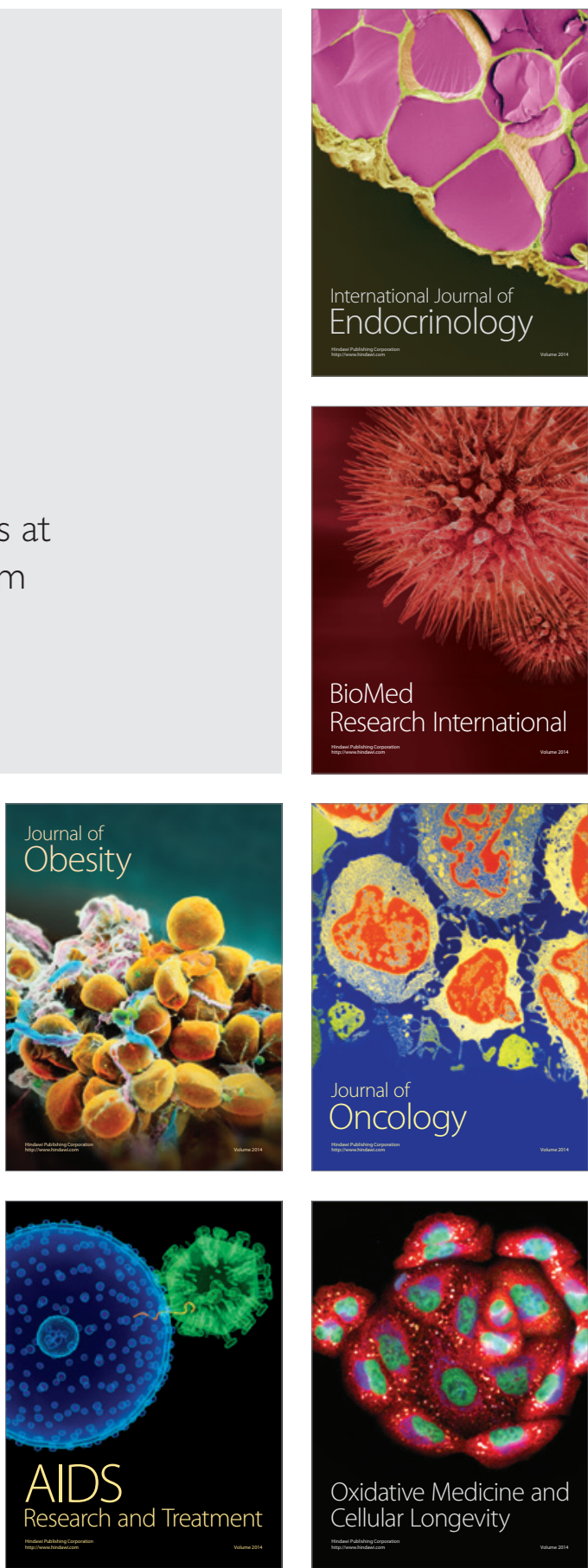